Computer-Aided Design (CAD) has all but replaced the drafting board for design work. Increased productivity and accuracy should be natural outcomes of using CAD. Going from paper drawings only to paper drawings based on CAD models to CAD models and no drawings, or Model Based Design (MBD), is a natural progression in today's world.

There are many advantages to MBD over traditional design methods. To make the most of those advantages, standards should be in place and the proper foundation should be laid prior to transitioning to MBD. However, without a full understanding of the implications of MBD and the proper control of the data, the advantages are greatly diminished.

Transitioning from a paper design world to an electronic design world means re-thinking how information gets controlled at its origin and distributed from one point to another. It means design methodology is critical, especially for large projects. It means preparation of standardized parts and processes as well as strong communication between all parties in order to maximize the benefits of MBD. 


\title{
Ares Upper Stage Processes to Implement Model Based Design - Going Paperless
}

\author{
Melanie Gregory ${ }^{1}$ \\ NASA Marshall Space Flight Center, Huntsville, Alabama, 35812
}

\begin{abstract}
Computer-Aided Design (CAD) has all but replaced the drafting board for design work. As today's world becomes more dependent upon technology, transitioning from paper drawings to Model Based Design (MBD) is a natural progression. Standards should be in place and the proper foundation should be laid prior to converting to MBD. Transitioning from a paper design world to an electronic design world means design methodology is critical, especially for large projects. It means preparation of standardized parts and processes as well as strong communication between all parties is needed in order to maximize the benefits of MBD.
\end{abstract}

\section{Nomenclature}

$C A D=$ Computer-Aided Design

$C M \quad=$ Configuration Management

DI $\quad=$ Desktop Instruction

$M B D=$ Model Based Design

$M B S E=$ Model Based Systems Engineering

$M S F C=$ Marshall Space Flight Center

NASA $=$ National Aeronautics and Space Administration

$P L M=$ Product Lifecycle Management

$2 D=$ Two-Dimensional

${ }^{1}$ Engineering Team Lead, EV32 


\section{Introduction}

The vast majority of design work today is accomplished using CAD. The advantages of doing so include the speed and ease in which the design package can be distributed, the increase in visualization of the design, and the ability to input the design model directly into manufacturing processes. In order to capitalize on the many advantages, groundwork should be in place prior to design initiation.

While CAD has been used for many years at the National Aeronautics and Space Administration (NASA), the scope of its use was greatly expanded during the design of the Ares I Flight Launch System. Previously, the CAD system was used to quickly make changes during the conceptual design phase to a preliminary model, or CAD was used to prepare the Two-Dimensional (2D) drawings, which were then released in the configuration management (CM) system as a paper drawing. When the decision was made for the Ares Upper Stage design to be model-based, the need for the processes to support such a decision was soon obvious. Due to the division of responsibilities for the various parts of Ares Upper Stage, the design responsibility was spread among various NASA centers as well as various design groups within the NASA centers, which further complicated the effort. The lessons learned and recommendations going forward are documented below.

\section{Laying the Proper Foundation}

Full MBD normally means that the design is completely electronic with all dimensions, tolerances, and annotations that would normally be on a 2D drawing now exist in the model. Because transitioning to full MBD is not trivial, the decision was made for the design of the Ares Upper Stage to be a hybrid MBD. This meant the CAD models would be under CM, but 2D drawings would also be prepared and released with the models. These 2D drawings had all the dimensions and notes, and none were in the models.

In order for MBD, whether full or hybrid, to be the most effective and useful design methodology, certain things must be in place from the very beginning of the design.

1. Tools

2. Documentation

3. Training

Each of these will be discussed in the following sections.

\section{Tools Required to Support MBD}

The first tool required to support MBD is the CAD tool. While most are designed to support MBD, not all are fully compliant with standard practices for defining a digital product data set ${ }^{1}$. The shortcomings or holes in the CAD tool being used must be understood and accounted for as needed if full MBD is adopted. If a hybrid MDB process is used, the decision must be made how the tool will be used in order to complete the design products.

The CAD tool should be configured or customized to meet the needs of the design community based on the requirements of the local process. The fewer selections each design engineer has to make in setting up each file, the more consistent each design product will be. The cost of configuring and customizing the $\mathrm{CAD}$ tool must be weighed against the cost of the design engineer's time and effort in 
setting up files prior to accomplishing true design work for optimization. Development of toolkits to use in conjunction with the CAD tool can save time without configuring or customizing the CAD tool itself.

CAD libraries to support the design engineers are essential to saving time as well as promoting consistency. Libraries of common standard hardware, such as bolts, washers, connectors and the like, not only save the design engineer time and eliminate duplication of effort in the modeling of these items, but also ensure the placement of these items will be in the proper orientation. Libraries can also be used to promote commonality and reduce the number of different but similar parts are used in the design. Libraries of standard notes, symbols, tables, formats, and materials should also be in place prior to design commencement.

Another tool required to support MBD is the Product Lifecycle Management (PLM) system. The CAD models must be controlled and placed in a locked state when the design is complete and released for manufacturing. Access to the models between inception and release must be decided and the proper controls put into place. If a single tool is used to store the models for a given design, the tool must be able to handle the volume of files and be available when needed. A new tool should be sufficiently tested and verified to function as needed to guarantee a smooth design cycle.

When the decision was made for the Ares Upper Stage design to be model-based, the need to control the models was realized, which had not been done in the past. In order to meet this requirement, a new PLM tool was brought on-line that had been in development for several years, but had not been used on any flight project, much less one of this magnitude. The CAD tool was in place, but its set up was not optimal. There were no CAD libraries in place and with a brand new PLM, the challenge was great to produce quality work that was properly controlled to meet the given schedule.

\section{Documentation to Support MBD}

Having a documented methodology for creating and managing the design is crucial. When designs are created in a uniform and robust manner, they are easier to share and be incorporated into the next higher assemblies. Because full MBD relies solely on the model, those models must relate correct dimensional data directly to manufacturing processes. While the CAD tool may allow the design engineer to do certain things, such as the overriding of dimensions, the documentation and processes must prevent that from occurring.

Foundational to uniform and robust CAD models is a CAD standard by which the models are created. A good CAD standard will define how the models are to be created, with sufficient detail to ensure uniformity across all design organizations without adding unnecessary overhead to the design engineer. It will include a naming convention in order to support such things as batch renaming, release into the CM system, CAD systems filename length limitations, and standard parts. It will define standard practices to be followed and include detailed requirements for CAD models at the part and assembly level. Drawing requirements should be included if full MBD is not incorporated.

Processes to support the configuration management of the CAD models from inception through release are needed to guarantee the model that is released for manufacturing is indeed the model manufacturing receives. Configuration management of the CAD models to support future changes and the ability to retrieve the configuration which was released are also necessary.

When the design of Ares began, a NASA CAD standard did not exist. Each design engineer modeled the way he thought best with little consistency from person to person. As the component models were assembled into larger and larger assembly models, failures of the assembly models began to 
increase. The causes of the failures indicated a CAD standard was needed for consistency and to define good modeling practices and requirements for the specific CAD tool being used. The Marshall Space Flight Center (MSFC) developed a CAD standard ${ }^{2}$ while design work was being done. While certainly less than ideal, the results of the models that were reworked to follow the CAD standard were soon obvious as the higher level assembly models opened more quickly and without failures. This CAD standard was the starting point for the NASA CAD standard ${ }^{3}$ that was later developed.

\section{Training}

Once the tools and documentation are in place to support MBD, training is needed for all parties involved in the design process. Design engineers must understand the requirements for modeling and using the PLM system, including the process for getting the design through the CM process to release the models for manufacturing. Reviewers and approvers of the design must also understand the PLM system and their role when the design is ready for their review and approval. Some training is best done in person, either in a classroom setting or one-on-one. Some can be accomplished through online modules, while others can be done through the use of manuals the individual completes on their own.

To support the MSFC CAD standard, a series of Desktop Instructions (DIs) were written to aid the design engineers in the implementation of the requirements in the CAD standard. These DIs consisted of the picks and clicks the design engineer would select using the CAD tool and included many screenshots for clarity. No new requirements were in the DIs, only recommended practices and methodologies for implementing the existing requirements.

\section{Recommendations}

For the optimal use of the MBD process, the tools, documentation, and training should all be in place prior to the beginning of a design project. There were other aspects that were considered lessons learned from the Ares design process. One recommendation was to have the design groups in close proximity to each other. Having the supporting technical personnel, such as materials, stress, and checking, would also be very desirable. Having the team in close proximity would make collaboration on the design quicker and much more straightforward.

Furthermore, there was a misconception that once the tools were in place the design engineer did not need to interact with the reviewers and approvers. Some design engineers thought they could "throw the design over the fence”, and the tool would see that it was approved out the other end. This, however, is not the case. Personal communication is needed between the design engineer and the other team members with today's technology just as much as in the past. The tools should make the design engineer's job easier, but does not relieve the design engineer of the responsibility of getting the design approved and resolving any issues that arise along the way.

Moreover, the best tools, documentation, and training can be in place but if there is insufficient governance or enforcement of the rules and requirements, then they are rendered somewhat useless. With the magnitude of the Ares design task, and the tools, documentation, and training being developed concurrently with the design, having all the CAD models created or revised to meet the requirements was not done proficiently. Schedule pressure and a lack of understanding of the advantages of being compliant with the new requirements hindered the implementation of the hybrid MBD process. 
For any significant change to the usual way of doing business, a culture or philosophy change is often needed. Buy-in to any new way of doing business is needed at all levels. The advantages of going to MBD must be real and understood for the change to be as effective as possible. Also to be considered, but which were not addressed here, are the classification of the design data for security purposes and data sharing across firewalls when required.

\section{Looking Ahead}

NASA has recently initiated a set of teams to determine how to implement Model Based Systems Engineering (MBSE) across all NASA centers. Benchmarking, understanding the current architectures, and developing pilots are some of the activities currently underway to accomplish the implementation of MBSE. MBD is part of this effort, and will include the hybrid MBD used for Ares Upper Stage.

There is also an effort to simplify the processes at MSFC and other NASA centers. Consolidation of tools is included in this effort. While painful in the near term, the expectation is that the long term benefits will be realized once the processes and tools are streamlined. The associated documentation and training will have to be updated accordingly in order for the benefits to be realized as well.

Because NASA typically does not mass produce parts or assemblies in-house, there are fewer benefits to MBD or MBSE than there is at a mass production facility. However, there are indeed advantages that NASA can and should pursue to make the most of its resources and stay on the cutting edge of design evolution.

\section{References}

${ }^{1}$ ASME Y14.41-2003, Digital Product Definition Data Practices

${ }^{2}$ MSFC-STD-3528, Computer-Aided Design (CAD) Standard

${ }^{3}$ NASA-STD-(I)-0007, NASA Computer-Aided Design Interoperability 
Engineering Directorate

Marshall Space Flight Ceniter

Ares Upper Steg,

Processes to linis id ment Model Based Design Going Paperless

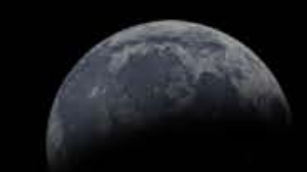

Melanie Gregery 


\section{CAD PROGRESSION AT NASA/MSFC}

- Electronic drafting boards 20-25 years ago

- 3D CAD models used during conceptual design 15-20 years ago

- Models used primarily for visualization

- 3D CAD models used to produce 2D drawings 15 years ago

- Models not controlled or governed formally

- Some test and non-flight hardware groups still function this way

- January 2008 Ares Upper Stage program mandated ModelBased Design (MBD)

- Agreement was made to be hybrid MBD - the 3D CAD model would be authoritative for the design, but 2D drawings would be prepared which would define the dimensions, tolerances, and notes.

- Additional resources needed to implement this to support schedules

- Looking Ahead

- NASA has initiated teams to implement Model Based Systems Engineering across all NASA centers

- Consolidation of tools is being studied 


\section{FOUNDATION REQUIREMENTS}

- Tools

- Documentation

- Training

** Resources and Support Personnel are required for Implementation** 


\section{TOOLS}

$\checkmark$ CAD Tool

- Must understand extent of compliance with standard practices for defining a digital product data set

- Must be configured/customized to meet the requirements of the local process

$\checkmark$ CAD Libraries

- Essential to saving time and promoting consistency/commonality

- Recommend libraries for:

- Standard hardware (bolts, washers, connectors, etc.)

- Standard notes

- Symbols

- Tables

- Drawing formats

- Materials

- Product Lifecycle Management (PLM) System

- Must be capable of controlling CAD/Drawing files according to local processes

- Must be capable of locking CAD/Drawing files when released 


\section{DOCUMENTATION}

- CAD Standard

- Defines model creation standards

- Defines naming conventions

- Defines standard practices at both part and assembly level

- Defines drawing requirements if needed

- Configuration Management (CM)

- Must define processes to enable the release of the models

- Must ensure the models released for manufacturing are those given to manufacturing

- Must be able to retrieve released models to support future changes

- Expedited change system needed to support manufacturing schedule

- Must be compatible with Quality Assurance organization for As-designed to As-built comparison

- Useful, but not required

- Desktop Instructions with picks and clicks to implement the requirements in the CAD Standard 


\section{MSFC Desktop Instructions List}

ED-CAD-DI-001 Workspace Use and Troubleshooting

ED-CAD-DI-002 Naming and Renaming Files in DDMS

ED-CAD-DI-003 Library Components

ED-CAD-DI-004 Standard Drawing Notes

ED-CAD-DI-005 Simplified Representation Creation and Maintenance

ED-CAD-DI-006 Creation of Skeleton Files

ED-CAD-DI-007 Standard Symbols

ED-CAD-DI-008 Updating Drawing Formats

ED-CAD-DI-009 MOD File Creation

ED-CAD-DI-010 Shrinkwrap Creation

ED-CAD-DI-011 Data Transfer

ED-CAD-DI-012 Casting and Forging Creation

ED-CAD-DI-013 Standard Barrel Panels

ED-CAD-DI-014 Cable Routing

ED-CAD-DI-015 Piping

ED-CAD-DI-016 Related Companion Files

ED-CAD-DI-017 Creating Standard Layers

ED-CAD-DI-018 Sheet Metal Parts

ED-CAD-DI-019 Adding Materials and Generating Mass

Properties
ED-CAD-DI-020 User-Defined Features

ED-CAD-DI-021 Gears, Splines, and Sprockets

ED-CAD-DI-022 Vendor Item Modeling

ED-CAD-DI-023 Exploded Views

ED-CAD-DI-024 Tables and Tabulated Drawings

ED-CAD-DI-025 Bulk Items

ED-CAD-DI-026 Verifying 3-Dimensional CAD Models

ED-CAD-DI-027 Revising CAD Documents and WT Parts

ED-CAD-DI-028 Physical Interface Matrix Creation

ED-CAD-DI-029 Modeling of Composites

ED-CAD-DI-030 Gathering Released Data in DDMS

ED-CAD-DI-031 Ground Strap Creation

ED-CAD-DI-032 Folder Structure

ED-CAD-DI-033 Create, Revise, Modify, and Promote

ED-CAD-DI-034 Modular Product Architecture

ED-CAD-DI-035 Computer-Aided Design (CAD) Management Prior to Release

ED-CAD-DI-036 Preparation and Processing of a DDMS Change Request for CAD and WT Part Release 
- Who

- Design Engineers

- Must understand the requirements for modeling and using the PLM system

- Must understand how to release the design through the CM system

- Must understand the big picture

- Reviewers/Approvers

- Must understand the PLM/CM system and their role

- Management

- Must understand the implications of MBD

$\checkmark$ How

- Individual training

- Online resources exist for most CAD tools

- Self-training using manuals

- One-on-one training of CAD super-users to new users

- Group training

- CAD tool vendor

- Outside vendor

- In-house training 


\section{RECOMMENDATIONS}

- Have Tools, Documentation, and Training in place prior to start of design project

- Test these on a small project first

- Have design personnel in close proximity

- Have supporting technical personnel (materials, stress, checking, etc.) in close proximity

- Make sure the design engineer owns the responsibility for getting the design through release

- Sufficient governance and enforcement of the rules and requirements

- Recognize when a culture change is needed

- People do not like change most of the time 
